tion the two large wards in which most of my cases of accident and of operation are treated were among the unhealthiest in the whole surgical division of the Glasgow Royal Infirmary, in consequence apparently of those wards being unfavourably placed with reference to the supply of fresh air; and I have felt ashamed when recording the results of my practice to have so often to allude to hospital gangrene or pyæmia. It was interesting, though melancholy, to observe that whenever all or nearly all the beds contained cases with open sores, these grievous complications were pretty sure to show themselves; so that I came to welcome simple fractures, though in them- selves of little interest either for myself or the students, because their presence diminished the proportion of open sores among the patients. But since the antiseptic treatment has been brought into full operation, and wounds and abscesses no longer poison the atmosphere with putrid exhalations, my wards, though in other respects under precisely the same circumstances as before, have completely changed their character; so that during the last nine months not a single instance of pyæmia, hospital gangrene or erysipelas has occurred in them.

As there appears to be no doubt regarding the cause of this change, the importance of the fact can hardly be exaggerated.

\title{
Results of Conservative Management of Internal Haemorrhoids
}

\author{
C. G. CLARK,* M.D., F.R.C.S., F.R.c.S.ED. ; G. R. GILES,* F.R.C.S. ; J. C. GOLIGHER,* CH.M., F.R.C.S., F.R.C.S.ED.
}

Brit. med. F., 1967, 2, 12-14

The standard non-operative treatment for internal haemorrhoids employed in this country is the submucous injection of $5 \%$ phenol in oil into the upper anal canal (Gabriel, 1948 ; Goligher, 1967). Graham-Stewart (1962) suggested that the improvement after injection treatment was possibly due to the carrier (almond oil) rather than to the phenol, and that injections of almond oil alone gave just as good results. Dissatisfaction with injection therapy led Blaisdell (1958) to introduce a method of ligation as an outpatient procedure, and this technique has been strongly advocated by Barron (1963, 1964). Some 18 months ago, impressed by the paucity of reports on the results of conservative treatment for haemorrhoids-and particularly on the lack of comparative results of different methods-we resolved to institute a controlled trial of the three methods mentioned above-namely, injection of $5 \%$ phenol in oil, injection of oil alone, and rubber ring ligation. In this paper we describe the organization of the trial and the results obtained to date.

\section{Material and Methods}

Patients for inclusion in the trial were selected at the rectal clinic. Those chosen were men and women with uncomplicated internal piles of first degree (no prolapse) or second degree (prolapse, reducing spontaneously). Patients with third-degree piles (gross prolapse, requiring digital reduction) were rejected as being suitable only for formal haemorrhoidectomy. Also rejected were patients with very early first-degree piles, because of the difficulty of applying the method of rubber ring ligation to such small haemorrhoids. The presence of a recent thrombosis or of an associated lesion such as an anal fissure or haematoma was a bar to acceptance in the trial. A few patients were rejected for social or psychological reasons-for example, because it would have been inconvenient for them to reattend for survey or because they were thought to be temperamentally unsuited for participation in an inquiry of this kind.

Once the surgeon had decided to accept a patient into the trial the choice of the method of treatment to be employed was out of his control. He simply opened the topmost of a pile of envelopes and carried out the form of therapy indicated in the enclosed chit of instruction, the envelopes having been - Rectal Clinic of the Professorial Surgical Unit, the General Infirmary
at Leeds, Leeds 1 . arranged at the start of the trial to give a random distribution of equal numbers of chits advising the three different methods. After the initial treatment was given, an appointment was made for the patient to be seen again three weeks later at a special follow-up clinic, when, if necessary, further treatment of the same kind as at the first visit was given, being repeated subsequently until there was good symptomatic relief. Thereafter the patient attended at 6 and 12 months for follow-up reviews. Careful note was made at the first consultation of the nature and severity of the symptoms as well as the extent of the piles. The patient's immediate reactions to the treatment were recorded at the time; and at follow-up visits any later ill-effects as well as symptomatic improvement were elicited and an objective assessment was made of the state of the piles.

The technique employed for administering the injections of $5 \%$ phenol in almond oil was as described elsewhere (Goligher, 1967) ; by means of a large proctoscope and a Gabriel syringe 3-5 ml. of the solution was placed in the submucosa at the upper pole of the haemorrhoid, all three primary haemorrhoidal sites being injected at the first visit. Further injections were given at subsequent visits as required. An identical plan was adopted in regard to injections of almond oil alone.

As regards rubber ring ligation, we used the equipment and technique developed by Barron $(1963,1964)$. A large tubular proctoscope was passed and the haemorrhoidal state assessed. Usually the most prominent pile was selected for treatment in the first instance, and, as a preliminary to the application of the rubber ligature, this haemorrhoid was brought specially into view by partial withdrawal and suitable angulation of the proctoscope, the aim being to have the inferior margin of the distal end of the instrument lying at or just below the pectinate line on the pile (see Diagram). While the proctoscope was held firmly in this position by an assistant, the Barron ligator, charged with two rubber ring ligatures, was inserted by the surgeon, the drum of the instrument being pressed against the mucosal covering of the pile, so that the lower edge of the distal end of the drum was maintained at least 1 in. $(0.6 \mathrm{~cm}$.) above the pectinate line. By means of the seizing forceps the substance of the suprapectinate part of the pile was drawn into the lumen of the drum and by closing the handle of the ligator the rubber ring ligatures were pushed off the end of the drum to constrict the projecting pile at its " neck." The seizing forceps, ligator, and proctoscope were then rapidly withdrawn. We accepted Barron's (1964) recommendation to treat only one 
pile at a time, so that if the patient had three sizable haemorrhoids he had to make two further visits at intervals of three weeks to complete the treatment.

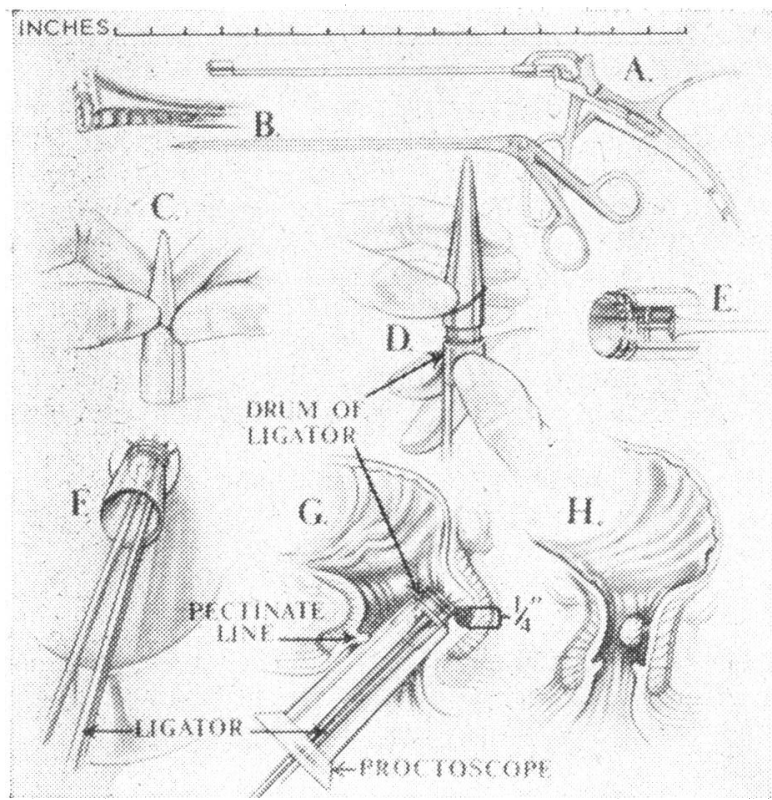

Reproduced from the second edition of Professor J. C. Goligher's Surgery of the Anus, Rectum, and Colon by pcrmission of the publishers.

\section{Results}

Sixty patients (48 men and 12 women) whose ages ranged from 21 to 74 have completed treatment on this trial and been followed up for at least six months. Details of the numbers of patients in each of the three treatment groups, together with frequency distribution and duration of symptoms, are recorded in Table I. The subsequent fate of these patients is shown in Table II, where the results of those who attended the six-month

Table I.-Details of Patients and Symptoms in the Three Treatment

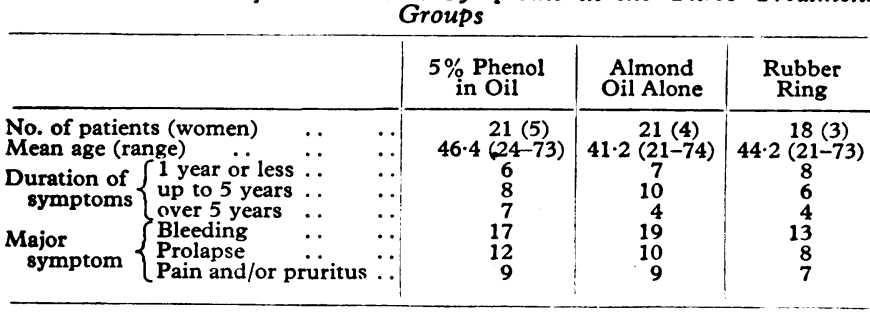

\begin{tabular}{|c|c|c|c|c|c|c|}
\hline & & & & $\begin{array}{c}5 \% \text { Phenol } \\
\text { in Oil }\end{array}$ & $\begin{array}{c}\text { Almond Oil } \\
\text { Alone }\end{array}$ & $\begin{array}{c}\text { Rubber } \\
\text { Ring }\end{array}$ \\
\hline \multicolumn{3}{|c|}{$\begin{array}{l}\text { Failed to complete treatment } \\
\text { Excluded } \ldots\end{array}$} & $\begin{array}{l}. \\
. \\
.\end{array}$ & $\begin{array}{l}1 \\
0 \\
0\end{array}$ & $2\left\{\begin{array}{l}0 \\
\text { Diverticulitis } \\
\text { Fissure } \\
2\end{array}\right.$ & $\begin{array}{l}4 \\
0 \\
1\end{array}$ \\
\hline $\begin{array}{l}\text { Satisfactory } \\
\text { Improved .. } \\
\text { Failed } \quad .\end{array}$ & $\begin{array}{l}\ddot{*} \\
\cdots\end{array}$ & $\begin{array}{l}\cdots \\
\cdots\end{array}$ & $\therefore$ & $\begin{array}{r}13 \\
4 \\
3\end{array}$ & $\begin{array}{l}9 \\
2 \\
6\end{array}$ & $\begin{array}{r}10 \\
2 \\
1\end{array}$ \\
\hline \multicolumn{3}{|c|}{ Completed and assessed. . } & $\cdots$ & 20 & 17 & 13 \\
\hline
\end{tabular}

review. are classified according to the patients' opinion of the outcome of treatment. A satisfactory result was where there were no symptoms, improved indicated worth-while treatment from the patient's point of view but with the persistence of some symptoms, and failure indicated symptoms as severe as, or worse than, those before treatment.

One patient in the phenol-injection group failed to complete treatment and no explanation was given. With rubber ring ligation, however, four patients failed to complete treatment, attending on one or two occasions only. In every case the reason given was the intense discomfort following ligation. Two patients in the almond-oil-injection group were excluded, one because of a subsequent diagnosis of diverticulitis, and the other because of the development of a fissure. Three patients failed to attend for review.

The overall result was satisfactory in about half of the patients treated by the two injection methods, but three-quarters of those treated by ligation had an excellent result. Failure of treatment was recorded in three patients after phenol-in-oil injections, and all were referred for haemorrhoidectomy. Six patients had persistent symptoms after almond oil injections, and four agreed to have further treatment with phenol in oil, of whom three responded satisfactorily. In only one of the cases completing treatment with rubber ring ligations was the method judged to have failed.

The majority of the patients attended on three or four occasions whatever method was used. This was because objective evidence did not necessarily parallel subjective improvement. The feature of injection therapy which has perhaps most strongly commended it in the past has been its efficacy in the control of bleeding. Table III shows the relation of cessation of bleeding to the number of treatments. In this respect the

TABLE III.-Effect of Treatment on Bleeding from Haemorrhoids

\begin{tabular}{|c|c|c|c|}
\hline & \multicolumn{3}{|c|}{ Cessation of Bleeding } \\
\hline & $\begin{array}{l}5 \% \text { Phenol } \\
\text { in Oil }\end{array}$ & $\begin{array}{l}\text { Almond } \\
\text { Oil Alone }\end{array}$ & $\begin{array}{c}\text { Rubber } \\
\text { Ring }\end{array}$ \\
\hline 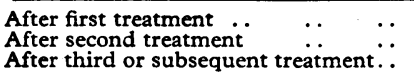 & $\begin{array}{r}12 \\
3 \\
2\end{array}$ & $\begin{array}{l}3 \\
7 \\
7\end{array}$ & $\begin{array}{l}8 \\
4 \\
1\end{array}$ \\
\hline Total & 17 & 17 & 13 \\
\hline
\end{tabular}

worst results were obtained with injections of almond oil alone, for patients often continued to bleed even after two series of such injections. Bleeding usually stopped within one or two days after injections of phenol in oil. It was not unexpected that bleeding should sometimes continue after rubber ring ligation, since only one pile is dealt with at a time in this technique.

An attempt was made to measure the objective changes resulting from treatment by comparing the number and size of haemorrhoids recorded at the time of initial diagnosis with the state of affairs present at six months. Table IV summarizes the findings, and shows that according to this criterion rubber ring ligation is vastly superior to the other forms of treatment for the larger piles. About half the patients show objective improvement after injections of phenol in oil, and there is little difference when almond oil alone is used. The results in small

TABLE IV.-Number and Size of Haemorrhoids Seen on Proctoscopy Before and six Months After Treatment in the Three Group of Patients

\begin{tabular}{|c|c|c|c|c|c|c|}
\hline & \multicolumn{2}{|c|}{$\begin{array}{l}5 \% \text { Phenol } \\
\text { in Oil }\end{array}$} & \multicolumn{2}{|c|}{$\begin{array}{l}\text { Almond Oil } \\
\text { Alone }\end{array}$} & \multicolumn{2}{|c|}{ Rubber Ring } \\
\hline & Bcfore & After & Before & After & Before & After \\
\hline $\begin{array}{l}\text { Large prolapsing piles } \\
\text { Small prolapsing piles } \\
\text { Piles, no prolapse } \quad .\end{array}$ & $\begin{array}{l}15 \\
24 \\
15\end{array}$ & $\begin{array}{r}7 \\
17 \\
6\end{array}$ & $\begin{array}{r}18 \\
21 \\
8\end{array}$ & $\begin{array}{r}15 \\
12 \\
1\end{array}$ & $\begin{array}{r}12 \\
21 \\
3\end{array}$ & $\begin{array}{l}1 \\
3 \\
5\end{array}$ \\
\hline
\end{tabular}

prolapsing piles are more difficult to interpret from Table IV, because included under this heading were some patients whose haemorrhoids had been reduced from second- to first-degree size by previous injection therapy. It may be that there is little difference in the two groups treated by injections, though the results with rubber ring ligations are again satisfactory. Only in the treatment of small or first-degree haemorrhoids was rubber ring ligation inferior to other treatments, and this may be because of the difficulty in applying the rubber rings to such piles. 


\section{Discussion}

Difficulties arise in the interpretation of the results of conservative treatment for internal haemorrhoids because of the frequent spontaneous remissions in symptoms that may occur in such cases, and also perhaps because of the fact that treatment by any method is often accompanied by simple advice on the avoidance of constipation, which might produce a slight amelioration in the condition. The number of patients so far treated in our trial does not allow of a full evaluation of all the factors, but all those in this series had had episodes of symptoms twice a year or more. A review at six months therefore seems reasonable to evaluate therapy; and the random selection of patients into treatment groups minimizes errors of interpretation association with multifactorial analysis.

Treatment by injection is generally painless and well tolerated by the patients. None of the complications which can arise from this treatment (Goligher, 1967) were encountered in these patients. On the other hand, treatment by ring ligation may be very uncomfortable, and was the reason for four patients refusing further treatment. Six other patients complained of some discomfort, of ten lasting for several days, and two patients lost time from work One of these patients developed painful groin glands two days after treatment. This disadvantage of treatment, however, was rewarded by a better objective endresult.

There was no doubt that the major symptom of bleeding was often dramatically relieved by injections of phenol in oil ; injections of almond oil alone were much less effective in this respect. Indeed, any improvement in the group treated by simple oil injections could well have resulted from spontaneous remission in view of the length of time elapsing before bleeding stopped. Objective assessment of injection therapy after six months, however, was disappointing, and even with the more efficacious phenol-in-oil injections there was only about a $50 \%$ improvement. This is in marked contrast to the results after rubber ring ligation, which were satisfactory in the majority of patients with the larger type of haemorrhoids, though not so satisfactory for first-degree piles. These objective assessments are supported by the reported symptomatic failures of treatment by both injection methods, though it should be emphasized that some patients who failed to respond to injections of almond oil alone secured relief with subsequent injections of $5 \%$ phenol in oil.
The results from the present study indicate the need for further evaluation of the conservative treatment of this common condition. One hundred patients have now been admitted to the trial, and those treated are to be observed after six months and one year. These preliminary results, however, indicate that the conventional treatment by injections may not be as satisfactory as is generally supposed. The long-term results of treatment by the ring applicator are generally encouraging, though our experience shows that this treatment is usually a good deal more uncomfortable for the patients and is not well tolerated by all of them. If it is to be used it is important to keep well above the pectinate line with the ligation, and to prescribe analgesics such as pethidine $100 \mathrm{mg}$. for the first two or three nights after application of the ring. The rubber ring treatment is better confined to prolapsing piles alone ; for firstdegree piles where bleeding is the main symptom injections with $5 \%$ phenol in almond oil remain the treatment of choice. There seems to be no advantage in the use of almond oil alone.

\section{Summary}

The treatment of haemorrhoids by conservative methods has been examined. Injection therapy with the use of phenol in almond oil was effective in controlling bleeding, but with almond oil alone it was not. A comparison between the results of injection therapy and the technique of rubber ring ligation showed objectively better results after six months with ligations. However, ligation was sometimes followed by pain, and a few patients refused to continue with this form of treatment.

These preliminary alternatives indicate that phenol in oil is still the best treatment for early first-degree piles. The results of ligation for second-degree piles are encouraging, but further evaluation is required.

\section{REFERENCES}

Barron, J. (1963). Amer. F. Surg., 105, 563.

- (1964). Personal communication.

Blaisdell, P. C. (1958). Surg. Gynec. Obstet., 106, 485.

Gabricl, W. B. (1948). The Principles and Practice of Rectal Surgery, 4 th ed. London.

Goligher, J. C. (1967). Surgery of the Anus, Rectum, and Colon, 2nd

ed. London. In press.

\title{
Iliac Vein Compression.-Its Relation to Iliofemoral Thrombosis and the Post-thrombotic Syndrome
}

\author{
F. B. COCKETT,* M.S., F.R.C.s. ; M. LEA THOMAS,* M.A., M.R.C.P., F.F.R., D.M.R.D. ; D. NEGUS,*† M.A., F.R.C.s.
}

Brit. med. f., 1967, 2, 14-19

It is 50 years since Homans (1917) first described the symptoms of swelling, ulceration, and pain which follow extensive thrombosis in the deep veins of the leg, and the "postphlebitic syndrome" has since been extensively investigated and documented. That venous thrombosis destroys the valves of the affected vein is established (Edwards and Edwards, 1937); that such valvular incompetence in the deep veins of the leg impairs the efficiency of the "muscle pump" has been proved by measurements of pressure changes in the veins of the foot or ankle (Pollack et al., 1949 ; Walker and Longland, 1950). The pattern of venous damage and recanalization has been demonstrated by phlebography (dos Santos, 1938 ; Bauer, 1940 ; Luke, 1941). The relation of "gravitational" ulcers to incompetent ankle perforating veins is established. The role of venous valvular incom- petence in the aetiology of the "postphlebitic syndrome" is clear.

A few early reports (Leriche, 1927 ; Jennings, 1933) suggested that in some cases iliac vein thrombosis might subsequently cause obstruction to the venous return from the limb. In 1950 a series of nine such cases of post-thrombotic occlusion of the iliac vein was described (Wanke and Gumrich, 1950). Similar iliac vein obstruction has been reported by Eufinger et al. (1961), Courty et al. (1962), Langeron and Lamoril (1963), and Goldstein et al. (1964).

* St. Thomas's Hospital, London S.E.1

† Present address: Department of Surgical Studies, Middlesex Hospital, I.ondon $\mathrm{W} .1$. 